\title{
Review
}

\section{The link between hyperglycaemia and diabetic nephropathy}

\author{
R.G. Larkins and M. E. Dunlop \\ University of Melbourne, Department of Medicine, Royal Melbourne Hospital, Melbourne, Victoria, Australia
}

\begin{abstract}
Summary. A large number of experimental studies in animals and retrospective or non-randomised prospective studies in humans provide support for the concept that the microvascular complications of diabetes mellitus are dependent on hyperglycaemia. This review focuses on four potential biochemical pathways linking hyperglycaemia to changes within the kidney which can plausibly be linked to the functional and structural changes characterising diabetic nephropathy. These four pathways are the polyol pathway, non-enzymatic glycation, glucose autoxidation and de novo synthesis of diacylglycerol leading to protein kinase $\mathrm{C}$ and phospholipase $\mathrm{A}_{2}$
\end{abstract}

activation. Rather than being independent, there are several potential interactions between these four pathways which may explain confusing and overlapping effects observed in studies examining inhibitors of individual pathways. As many of the steps which follow on glucose metabolism are subject to modification by dietary and pharmacological means, the further delineation of the pathogenetic sequence leading to tissue damage in diabetes should allow a logical and effective approach to the prevention or treatment of the complications of diabetes.
Despite an increased ability to control the metabolic disturbances of diabetes mellitus, diabetic nephropathy remains a major cause of morbidity and mortality. It is now the most common underlying problem in patients presenting for management of end-stage renal failure in many Western countries, accounting for over $25 \%$ of the cases. Whilst controversial, most data indicate that the liability to develop diabetic nephropathy is linked to the overall control of the blood glucose level. It should be remembered that the strongest evidence for this in human subjects comes from non-randomised prospective studies [1] or from retrospective studies [2] and that some similar retrospective studies have shown no clear association between the degree of glycaemic control and the risk of diabetic nephropathy [3]. Animal studies have provided fairly direct support for an aetiological link between hyperglycaemia and histological changes in the kidney [4], but until results from the Diabetes Control and Complications Trial are available [5], there is no absolute certainty of the link in humans between hyperglycaemia and diabetic nephropathy. However, the most reasonable position to take at this stage, and the departure point for the discussion in the rest of this review, is that hyperglycaemia sets in motion a series of biochemical disturbances in critical tissues (including the kidney) leading to functional changes, followed by irreversible structural changes and finally the features that we recognise as clinical disease. Whatever role we attribute to hyperglycaemia, it is apparent that this sequence is very much affected by genetic and environmental (such as dietary) factors that lead to a variable expression of disease even in those with a similar duration and severity of metabolic disturbance.

Having accepted the surmise that hyperglycaemia is directly linked to the development of diabetic nephropathy, there is no shortage of plausible biochemical mechanisms which could lead to functional changes and/or tissue damage. Because of available space, this review will focus on four biochemical pathways which have recently been the subject of extensive investigation. Where possible, potential links with functional and structural changes in the kidney will be described. It will be emphasised that the mechanisms are not mutually exclusive and that there is the likelihood of important interactions between them.

\section{The polyol pathway (Fig. 1)}

A potential link between the formation of sorbitol from glucose catalysed by aldose reductase in tissues of diabetic subjects and the development of diabetic complications was first recognised more than 20 years ago [6-8]. Evidence for participation of the polyol pathway in the pa- 


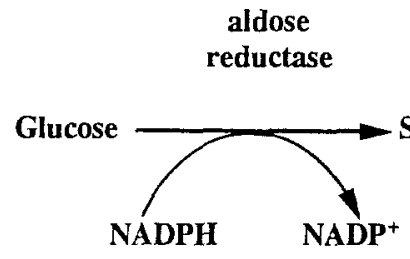

(3)
(1)

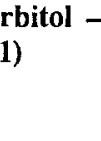

$(4)$ sorbitol

dehydrogenase

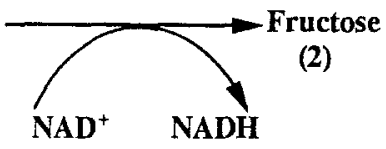

(4)
1

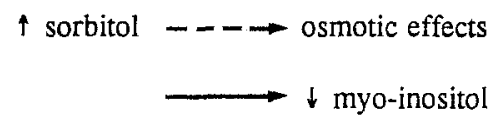

2.

3.
4.

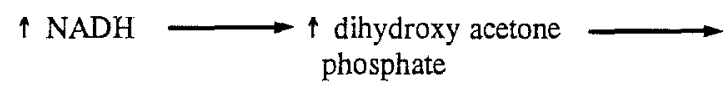

tissue damage

$\downarrow$ phosphoinoside signalling

$\uparrow$ protein cross-linking

$\uparrow$ oxidative damage

$\uparrow$ cyclooxygenase activity

$\uparrow$ triose phosphates for de novo diacylglycerol pathway

$\uparrow$ de novo diacylglycerol pathway
Fig. 1. The aldose reductase pathway with demonstrated or postulated biochemical consequences of potential relevance to the pathogenesis of diabetic nephropathy (and other complications of diabetes). GSH, reduced glutathione; GSSG, oxidized glutathione thogenesis of diabetic nephropathy comes mainly from animal data using aldose reductase inhibitors. Although the results from different laboratories have not been uniform, most groups have been able to demonstrate that if administered from the time of induction of diabetes by streptozotocin in rats, a variety of aldose reductase inhibitors will reduce the subsequent increase in urinary albumin excretion [9-12]. The increased glomerular filtration rate of early diabetes may also be normalized $[11,13]$ although this is not required for the effect on albumin excretion to be observed [12]. Human data relating to the effects of aldose reductase inhibitors in diabetic nephropathy are relatively sparse. It has recently been shown that the aldose reductase inhibitor ponalrestat decreases the hyperfiltration observed in some diabetic subjects [14].

Further evidence that the polyol pathway may play a role in diabetic complications has come from using galactose feeding of non-diabetic animals to achieve increased polyol accumulation without the other metabolic disturbances of diabetes. Galactose is converted to galactitol by aldose reductase, and accumulates in tissues. It has been clearly demonstrated that galactose-feeding leads to the development of retinal lesions resembling those of diabetes in rats and dogs [15-17]. It also leads to changes in kidney physiology and structure resembling the effects of diabetes $[18,19]$, although the effectiveness of aldose reductase inhibitors in preventing the changes has differed between studies.
The mechanisms by which excessive activity of the polyol pathway could lead to complications of diabetes are complex and are summarised schematically in Figure 1. It was initially considered that osmotic effects of sorbitol accumulation might damage tissues [20], but even in the lens of the eye where an osmotic effect is potentially the greatest sorbitol levels do not exceed $2 \mathrm{mmol} / \mathrm{l}$, even after severe hyperglycaemia [21]. Moreover, although galactose feeding leads to an increase in nerve water content, similar changes are not seen in experimental diabetes [22]. These and other observations make osmotic effects unlikely to be the major mechanisms of tissue damage associated with the polyol pathway.

Greene and co-workers have suggested that tissue damage secondary to polyol pathway activity is caused by the impairment of myo-inositol uptake consequent to sorbitol accumulation $[23,24]$. This causes depletion of tissue phosphoinositides, and would have the potential to result in decreased phosphatidylinositol bisphosphate hydrolysis and decreased diacylglycerol formation [25]. Diacylglycerol is the regulatory activator of protein kinase $\mathrm{C}$ [26] which in turn activates sodium-potassium ATPase. Although there is evidence supporting parts of this sequence especially in nerve [27] the situation in the kidney appears to be different. Diacylglycerol is produced in increased amounts by a de novo synthetic pathway in glomeruli [28] and cultured mesangial cells [29], and this is associated with increased, not decreased, protein ki- 
nase $C$ activity. Decreased myo-inositol uptake and content, and polyphosphoinositide turnover can be demonstrated in glomeruli from diabetic rats [28], and this could contribute to impaired inositol trisphosphate release, which in turn could account for poor $\mathrm{Ca}^{2+}$ mobilisation and mesangial cell contractile activity in mesangial cells cultured in conditions designed to simulate the diabetic environment $[29,30]$.

Even by 1971 it was recognised that important alterations in the ratio of pyridine nucleotides would occur as a result of flux through the polyol pathway [7]. Reduction of glucose to sorbitol utilises NADPH and oxidation of sorbitol to fructose catalysed by sorbitol dehydrogenase increases NADH.

Increased NADPH utilization by activity of the aldose reductase pathway could have several consequences in the cell. In particular, it could be linked to increased prostaglandin synthesis in two possible ways. It would be expected to lead to decreased levels of reduced glutathione (GSH), which in turn might be associated with increased endogenous hydrogen peroxide and cyclooxygenase activity [32]. Alternatively, the NADPH utilization would be expected to increase activity of the pentose phosphate pathway, providing triose phosphate intermediates for the de novo synthetic pathway for diacylglycerol (and subsequently prostaglandin synthesis). The de novo diacylglycerolsynthetic pathway would be enhanced by the increased NADH:NAD ${ }^{+}$ratio, which would favour the formation of dihydroxyacetone at the triose isomerase step. The de novo pathway of diacylglycerol formation and its relation to prostaglandin synthesis is described more fully in a later section of this review.

The final consequence of increased flux through the aldose reductase pathway which could be important in diabetic complications is increased formation of fructose. Non-enzymatic fructosylation of tissues occurs at a considerably increased rate compared with glycation [33] and fructose levels are increased up to 23 -fold in tissues such as the lens where the aldose reductase pathway is active [34]. These observations provide an explanation for the observed effects of aldose reductase inhibitors in decreasing collagen fluorescence in diabetic rats $[33,35]$, an effect shared by aminoguanidine, an inhibitor of formation of advanced glycation end products. This provides a link between the aldose reductase pathway and non-enzymatic glycation.

It can be seen that there are several consequences of increased flux of glucose through the aldose reductase pathway which could have relevance to diabetic complications. There are abundant data from animal studies supporting a role for some of these effects in the early stages of diabetic nephropathy, but it should be emphasised that data in humans are very limited, and no studies have convincingly demonstrated reversal of established pathological changes following inhibition of aldose reductase.

\section{Non-enzymatic glycation}

It has been known for many years that glucose can form glycation products with protein (Schiff bases), by a nonenzymatic process dependent on the glucose concentra- tion. The Schiff bases rearrange to form the more stable Amadori products. These early glycation reactions are reversible and therefore reach a steady state, even in longlived proteins [36]. Particular interest has focused in recent years on the subsequent steps which can occur. The early glycation products may undergo a complex series of chemical rearrangements to form advanced glycation end products (AGEs), which accumulate over a life-time. By interacting with other proteins, they may form cross-links with significant structural effects. Aging in non-diabetic subjects is associated with progressive accumulation of AGEs, but the process is greatly accelerated by diabetes. As it has been shown that a highly significant correlation exists between accumulated levels of AGEs on collagen and severity of diabetic retinopathy [37], a pathogenetic role for them has been suggested. This is supported by experiments showing that an inhibitor of the advanced glycation product formation, aminoguanidine, prevented basement membrane thickening in diabetic rats [36]. Many other consequences of non-enzymatic glycation have been postulated which might be of relevance to diabetic complications, but they are beyond the scope of this review. It should, however, be emphasised that there is an important potential link between the polyol pathway and non-enzymatic glycation, with aldose reductase inhibitors having the ability to simulate the action of aminoguanidine in inhibiting diabetes-induced fluorescence in rat collagen $[33,35]$. The description of specific macrophage receptors for advanced glycation end products and their down-regulation by insulin [38] provides an additional level of complexity. Moreover, non-enzymatic glycation of reactive amino groups in model proteins increases the rate of free radical production by nearly 50-fold [39], providing a link with the oxidative damage described in the next section.

\section{Glucose autoxidation}

The metabolism of glucose can lead to the formation of reactive oxygen species [40]. This process is catalysed by metal ions. Oxidative modification of lipids and proteins can follow. It has been postulated that oxidative processes are major mechanisms for tissue damage in diabetes [41]. With respect to the kidney, the analogy between diabetic nephropathy and atherosclerosis has been drawn [42]. Oxidative modification of low density lipoproteins (LDL) is a key step in the formation of foam cells in atherosclerosis, as such modification is required to allow macrophage receptors to recognise LDL [43]. It has been demonstrated that high fat diets exacerbate certain types of experimental nephropathy [44], perhaps by a similar mechanism to that occurring in atherosclerosis. Glucoseinduced oxidative modification of lipids, especially LDL, would be expected to exacerbate this process. Controlled studies of the effect of diets of varying fat content or of pharmacological modification of hyperlipidaemia on the progress of diabetic nephropathy in humans are not yet available, but an uncontrolled study indicated a relationship between serum lipid levels and rate of progression of diabetic nephropathy in humans [45]. 


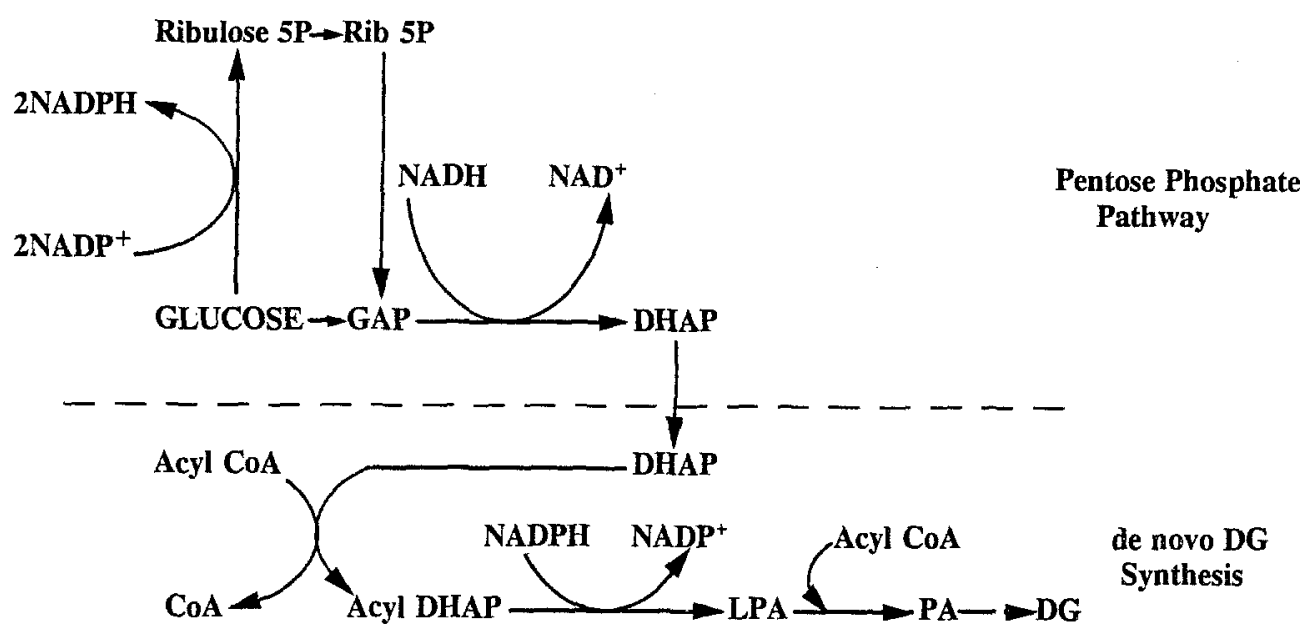

Fig. 2. The de novo synthetic pathway of diacylglycerol (DG) formation from glucose. It is favoured by the altered ratios of pyridine nucleotides consequent upon increased aldose reductase pathway activity demonstrated in Figure 1.DG is the physiological regulator of protein kinase $\mathrm{Cac}$ tivity, which in turn can regulate phospholipase $A_{2}$ activity and prostaglandin production. Ribulose 5P, ribulose 5-phosphate; Rib 5P, ribose 5-phosphate; GAP, glyceraldehyde 3-phosphate; DHAP, dihydroxyacetone phosphate; LPA, lysophosphatidic acid; PA, phosphatidic acid
Although human data are lacking, oxidative damage to proteins dependent on oxygen radical generation from glucose metabolism might also be important in the genesis of diabetic nephropathy.

\section{De novo synthesis of diacylglycerol, protein kinase $C$ activation, phospholipase $A_{2}$ activation and increased prostanoid synthesis (Fig. 2)}

Following some earlier observations on glucose conversion to lipids and phospholipids in mouse pancreatic islets [46] it was shown that glucose can be metabolised directly to diacylglycerol, by a process involving conversion of dihydroxyacetone phosphate to lysophosphatidic acid, phosphatidic acid and diacylglycerol in neonatal rat pancreatic islets [47]. This pathway has now been shown to operate in many other tissues, including retinal capillary endothelial cells $[48,49]$ heart from diabetic rats [50], granulation tissue in a skin chamber exposed to high glucose concentrations [51], glomeruli from diabetic rats [28] and mesangial cells isolated from diabetic rats or cultured under conditions designed to simulate diabetes [29].

Diacylglycerol is the regulatory stimulator of protein kinase C [26], and its elevation is the presumed mechanism for the elevated protein kinase $C$ activity observed in several tissues obtained from diabetic animals or exposed in vitro to high glucose concentrations, including rat retinal capillary endothelial cells [49], rat granulation tissue [52], rat renal glomeruli $[28,53-55]$ and rat mesangial cells [29]. Activation of protein kinase $C$ in turn could have several consequences of potential importance in the pathogenesis of diabetic complications [48] including enhanced DNA synthesis and growth rate in vascular cells [56], increased hormone and growth factor receptor turnover [57], increased smooth muscle contraction [58] and increased cyclic AMP responses to different hormones in vascular cells [59].

Another consequence of increased protein kinase $\mathrm{C}$ activity may be increased prostaglandin synthesis. Increased glomerular and mesangial cell prostaglandin production in experimental diabetes was demonstrated several years ago $[60,61]$ and has been confirmed by many investigators. Part of the mechanism for increased prostaglandin synthesis is presumably increased conversion of arachidonic acid to prostaglandins dependent on cyclooxygenase activation $[62,63]$ perhaps related to altered redox state of the cell due to aldose reductase activity $[12,31]$. In addition, however, and probably playing a larger part in the increased glomerular prostaglandin production, increased phospholipase $\mathrm{A}_{2}$ activity has been demonstrated in glomeruli and mesangial cells from diabetic rats $[12,29,64]$. Phospholipase $A_{2}$ activation has been attributed to activation of protein kinase $C$ [53-55] directly or via phosphorylation of lipocortin [65]. There are of course many ways in which elevated production of vasodilatory prostaglandins and/or thromboxane $\mathrm{A}_{2}$ could lead to the early functional and later structural changes in the kidney in diabetes, and much research has been devoted to delineating their role. Suffice it to say that it seems likely that overproduction of vasodilatory prostaglandins by renal glomeruli plays a role in the early renal hyperfusion and hyperfiltration $[62,63,66-68]$ although their exact contribution is controversial $[69,70]$. The reduction in mesangial cell contractility induced by prostaglandin $E_{2}$ and prostacyclin in vitro [30,60] suggests that increased production of vasodilatory prostaglandins could also affect glomerular permeability. A recent report also suggests an important role for overproduction of thromboxane $\mathrm{A}_{2}$. Treatment of diabetic rats with a thromboxane synthetase inhibitor greatly reduced the degree of albuminuria and the degree of renal type IV collagen gene expression [71]. The latter effect may well have resulted from decreased pressure within the glomerular loops, suggesting that thromboxane $\mathrm{A}_{2}$ might contribute to increased glomerular efferent arteriolar tone in diabetes.

\section{Conclusion}

From this brief review, it can be seen that there are several potential mechanisms by which hyperglycaemia could lead to a sequence of biochemical events culminating in the physiological changes characterising early diabetes. The later structural changes can be understood as longterm consequences of the biochemical and physiological changes. The exact role played by these processes, and the 
contribution of many other physiological and biochemical changes observed in diabetes which have not been dealt with in this review remain to be clarified. However, as many of the processes can be modified by dietary or pharmacological means, it is essential that the detailed sequence of events in the pathogenesis of diabetic nephropathy be defined by continuing and extending the combination of cell biology, animal and human experimentation that has led to such dramatic advances in our knowledge in the last few years.

Acknowledgements. Experimental work of the authors referred to in this manuscript was supported by grants from National Health and Medical Research Council of Australia, Hoechst Diabetes Research and Development Fund, the Kellion Diabetes Foundation and the Diabetes Australia Research Trust.

\section{References}

1. Pirart $\mathrm{J}$ (1978) Diabetes mellitus and its degenerative complications: a prospective study of 4400 patients observed between 1947 and 1973. Diab Care 1:168-188

2. Krolewski AS, Warram JH, Christlieb AR, Busick EJ, Kahn CR (1985) The changing natural history of nephropathy in type 1 diabetes. Am J Med 78: 785-794

3. Deckert T, Poulsen JE (1981) Diabetic nephropathy: fault or destiny? Diabetologia 21: 178-183

4. Kern TS, Engerman RL (1990) Arrest of glomerulopathy in diabetic dogs by improved glycaemic control. Diabetologia 33: $522-525$

5. The DCCT Research Group (1987) Diabetes control and complications trial (DCCT): results of feasibility study. Diab Care 10: 1-19

6. Gabbay KH, Merola LO, Field RA (1966) Sorbitol pathway: presence in nerve and cord with substrate accumulation in diabetes. Science 151:209-210

7. Travis SF, Morrison AD, Clements RS Jr, Winegrad AI, Oski FA (1971) Metabolic alterations in the human erythrocyte produced by increase in glucose concentration: the role of the polyol pathway. J Clin Invest 50:2104-2112

8. Gabbay KH (1973) The sorbitol pathway and the complications of diabetes. N Engl J Med 288: 831-836

9. Beyer-Mears A, Cruz E, Edelist T, Varagiannis E (1986) Diminished proteinuria in diabetes mellitus by sorbinil, an aldose reductase inhibitor. Pharmacology 32: 52-60

10. McCaleb ML, Sredy J, Millen J, Ackerman DM, Dvornik D (1988) Prevention of urinary albumin excretion in 6 month streptozotocin diabetic rats with the aldose reductase inhibitor tolrestat. J Diab Comp 2: 16-18

11. Tilton RG, Chang K, Pugliese $\mathrm{G}$ et al. (1989) Prevention of hemodynamic and vascular albumin filtration changes in diabetic rats by aldose reductase inhibitors. Diabetes 37 : 12581270

12. Chang WP, Dimitriadis E, Allen T, Dunlop ME, Cooper M, Larkins RG (1991) The effect of aldose reductase inhibitors on glomerular prostaglandin production and urinary albumin excretion in experimental diabetes mellitus. Diabetologia 34:225-231

13. Goldfarb S, Ziyadeh FN, Kern EFO, Simmons DA (1991) Effects of polyol-pathway inhibition and dietary myo-inositol on glomerular hemodynamic function in experimental diabetes mellitus in rats. Diabetes $40: 465-471$

14. Pedersen MM, Christiansen JS, Mogensen CE (1991) Reduction of glomerular hyperfiltration in normoalbuminuric IDDM patients by 6 mo of aldose reductase inhibition. Diabetes 40 : 527-531

15. Frank RN, Keirn RJ, Kennedy A, Frank KW (1983) Galactoseinduced retinal capillary basement membrane thickening: prevention by sorbinil. Invest Ophthalmol Vis Sci 24:1519-1524
16. Robison WG Jr, Kador PF, Kinoshita JH (1983) Retinal capillaries: basement membrane thickening by galactosemia prevented with aldose reductase inhibitor. Science 221:1177-1179

17. Kador PF, Akagi Y, Terubayashi H, Wyman M, Kinoshita JH (1988) Prevention of pericyte ghost formation in retinal capillaries of galactose-fed dogs by aldose reductase inhibitors. Arch Ophthalmol 106: 1099-1102

18. Bank N, Coco M, Aynedjian HS (1989) Galactose feeding causes glomerular hyperperfusion: prevention by aldose reductase inhibition. Am J Physiol 256: F994-F999

19. Das A. Frank RN, Zhang NL (1990) Sorbinil does not prevent galactose-induced glomerular capillary basement membrane thickening in the rat. Diabetologia 33:515-521

20. Kinoshita JH (1974) Mechanism initiating cataract formation. Invest Ophthalmol 13:713-724

21. Heaf DJ, Galton DJ (1975) Sorbitol and other polyols in lens, adipose tissues and urine in diabetes mellitus. Clin Chim Acta 63: $41-47$

22. Willars GB, Lambourne JE, Tomlinson DR (1987) Does galactose feeding provide a valid model of consequences of exaggerated polyol-pathway flux in peripheral nerve in experimental diabetes? Diabetes 36: 1425-1431

23. Greene DA, Lattimer SA, Sima AAF (1987) Sorbitol, phosphoinositides, and sodium-potassium-ATPase in the pathogenesis of diabetic complications. N Engl J Med 316:599 606

24. Greene DA, Lattimer SA, Sima AAF (1988) Are disturbances of sorbitol, phosphoinositide, and $\mathrm{Na}^{+}-\mathrm{K}^{+}$-ATPase regulation involved in pathogenesis of diabetic nephropathy? Diabetes 37 : 688-693

25. Berridge MJ (1984) Inositol trisphosphate and diacylglycerol as second messengers. Biochem J 220:345-360

26. Nishizuka Y (1984) The role of protein kinase $C$ in cell surface signal transduction and tumour promotion. Nature 308: 693-697

27. Greene DA, Lattimer SA (1986) Protein kinase C agonists acutely normalize decreased ouabain-inhibitable respiration in diabetic rabbit nerve. Implications for $(\mathrm{Na}, \mathrm{K})$-ATPase regulaw tion and diabetic complications. Diabetes $35: 242-245$

28. Craven PA, De Rubertis FR (1989) Protein kinase C is activated in glomeruli from streptozotocin diabetic rats. Possible mediation by glucose. J Clin Invest $83: 1667-1675$

29. Larkins RG, Dunlop ME (1991) Prostaglandins, polyols and mesangial cell function in experimental diabetes. In: Rifkin $\mathrm{H}$, Colwell JA, Taylor SI (eds) Diabetes 1991. Excerpta Medica, Amsterdam, pp 180-183

30. Dunlop ME, Larkins RG (1990) Insulin-dependent contractility of glomerular mesangial cells in response to angiotensin II, platelet activating factor and endothelin is attenuated by prostaglandin $\mathrm{E}_{2}$. Biochem $\mathrm{J} 272: 561-568$

31. Craven PA, De Rubertis FR (1989) Sorbinil suppresses glomerular prostaglandin production in the streptozotocin diabetic rat. Metabolism 38: 649-654

32. Kuehl FA Jr, Egan RW (1990) Prostaglandins, arachidonic acid, and inflammation. Science $210: 978-983$

33. Suarez G, Rajarani R, Bhurjan KC, Oronsky L, Goidi JA (1988) Administration of aldose reductase inhibitor induces a decrease of collagen fluorescence in diabetic rats. J Clin Invest 82:624-627

34. Gabbay KH, Kinoshita JH (1972) Mechanisms of development and prevention of cataracts. Isr J Med Sci 8: 1557-1561

35. Odetti PR, Borgoglio A, De Pascale A, Rolandi R, Adezati L (1990) Prevention of diabetes-increased aging effect on rat collagen-linked fluorescence by aminoguanidine and rutin. Diabetes 39: 796-801

36. Brownlee M, Cerami A, Vlassara H (1988) Advanced glycosylation end products in tissue and the biochemical basis of diabetic complications. N Engl J Med 318: 1315-1321

37. Monnier VM, Vishwanath V, Frank KE, Elmets CA, DauchotO, Kohn RR (1986) Relation between complications of type 1 diabetes mellitus and collagen-linked fluorescence. $\mathrm{N}$ Engl $\mathrm{J}$ Med 314: 403-408

38. Vlassara $\mathrm{H}$, Brownlee $\mathrm{M}$, Cerami A (1985) High-affinity receptor-mediated uptake and degradation of glucose-modified pro- 
teins: a potential mechanism for the removal of senescent macromolecules. Proc Natl Acad Sci USA 82: 5588-5592

39. Mullarkey CJ, Edelstein D, Brownlee M (1990) Free radical generation by early glycation products: a mechanism for accelerated atherogenesis in diabetes. Biochem Biophys Res Commun 173: 932-939

40. Hunt JV, Smith CCT, Wolff SP (1990) Autoxidative glycosylation and possible involvement of peroxides and free radicals in LDL modification by glucose. Diabetes 39: 1420-1424

41. Wolff SP, Dean RT (1987) Glucose autoxidation and protein modification: the potential role of autoxidative glycosylation in diabetes. Biochem J 245: 243-250

42. Diamond JR (1991) Analogous pathobiologic mechanisms in glomerulosclerosis and atherosclerosis. Kidney Int 39 [Suppl 31]: S25-S34

43. Steinberg D, Parthasarathy S, Carew TE, Khoo JC, Witztum JL (1989) Beyond cholesterol. Modifications of low-density lipoprotein that increase its atherogenicity. N Engl J Med 320: 915923

44. Moorhead JF (1991) Lipids and progressive kidney disease. Nephron 57: 453-459

45. Mulec H, Johnson SA, Björck S (1990) Relationship between serum cholesterol and diabetic nephropathy. Lancet 1: 1537 1538

46. Berne C (1975) The metabolism of lipids in mouse pancreatic islets. The biosynthesis of triacylglycerols and phospholipids. Biochem J 152: 667-673

47. Dunlop ME, Larkins RG (1985) Pancreatic islets synthesize phospholipids de novo from glucose via acyl-dihydroxyacetone phosphate. Biochem Biophys Res Commun 132: 467-473

48. Lee T-S, Saltsman KA, Ohashi H, King GL (1989) Activation of protein kinase $C$ by elevation of glucose concentration: proposal for a mechanism in the development of diabetic vascular complications. Proc Natl Acad Sci USA 86: 5141-5145

49. Lee T-S, MacGregor LC, Fluharty SJ, King GL (1989) Differential regulation of protein kinase $\mathrm{C}$ and $(\mathrm{Na}, \mathrm{K})$-adenosine trisphosphatase activities by elevated glucose levels in retinal capillary endothelial cells. J Clin Invest 83: 90-94

50. Okamura K, Akijama N, Hashimoto H, Ogawa K, Satake T (1988) Alteration of 1,2-diacylglycerol content in myocardium from diabetic rats. Diabetes 37: 1168-1171

51. Wolf BA, Williamson JR, Eason RA, Chang K, Sherman WR, Turk J (1991) Diacylglycerol accumulation and microvascular abnormalities induced by elevated glucose levels. J Clin Invest 87: $31-38$

52. Williamson JR, Ostrow E, Eades D, Chang K, Allison W, Kilo C, Sherman WR (1990) Glucose-induced vascular functional changes in nondiabetic rats: prevention by an aldose reductase inhibitor. J Clin Invest 85: 1167-1172

53. Craven PA, Patterson MC, De Rubertis FR (1987) Role for protein kinase $\mathrm{C}$ in $\mathrm{A} 23187$ induced glomerular arachidonate release and $\mathrm{PGE}_{2}$ production. Biochem Biophys Res Commun 149: 658-664

54. Craven PA, Patterson MC, De Rubertis FR (1988) Role for protein kinase $\mathrm{C}$ in the modulation of glomerular $\mathrm{PGE}_{2}$ production by angiotensin II. Biochem Biophys Res Commun 152: 14811489

55. Craven PA, Davidson CM, De Rubertis FR (1990) Increase in diacylglycerol mass in isolated glomeruli by glucose from de novo synthesis of glycerolipids. Diabetes 39: 667-674

56. Kariya K, Kawahara Y, Tsuda T, Fukuzaki H, Takai Y (1987) Possible involvement of protein kinase $\mathrm{C}$ in platelet-derived growth factor-stimulated DNA synthesis in vascular smooth muscle cells. Atherosclerosis 63: 251-255

57. Hachiya HL, Takayama S, White MF, King GL (1987) Regulation of insulin receptor internalization in vascular endothelial cells by insulin and phorbol ester. J Biol Chem 262: 6417-6424

58. Caramelo C, Okada K, Tsai P, Schrier RW (1989) Phorbol esters and protein kinase $C$ in vascular smooth muscle contraction. Am J Physiol 253: H1365-H1371

59. Limas CJ, Limas C (1985) Phorbol ester- and diacylgiycerolmediated desensitization of cardiac $\beta$-adrenergic receptors. Circ Res 57: 443-449

60. Kreisberg JI, Patel PY (1983) The effects of insulin, glucose and diabetes on prostaglandin production by rat kidney glomeruli and cultured glomerular mesangial cells. Prostaglandins Leukotrienes Med 11: 431-442

61. Schambelan M, Blake S, Sraer J, Bens M, Nivez MP, Wahbe F (1985) Increased prostaglandin production by glomeruli isolated from rats with streptozotocin-induced diabetes mellitus. J Clin Invest $75: 404-412$

62. Moel DI, Safirstein RL, McEvoy RC, Hsueh W (1987) Effect of aspirin on experimental diabetic nephropathy. J Lab Clin Med 110: $300-307$

63. Sarubbi D, McGiff JC, Quilley J (1989) Renal vascular responses and eicosanoid release in diabetic rats. Am J Physiol 257: F762F768

64. Craven PA, Patterson MC, De Rubertis FR (1988) Role of enhanced arachidonate availability through the phospholipase $A_{2}$ pathway in the mediation of increased prostaglandin synthesis by glomeruli from diabetic rats. Diabetes 37: 429-435

65. Hirata F, Matsuda K, Notsu Y, Hattori T, del Carmine R (1984) Phosphorylation of a tyrosine residue of lipomodulin in mitogenstimulated murine thymocytes. Proc Natl Acad Sci USA 81: $4717-4721$

66. Kasiske BL, O'Donnell MP, Keane WF (1985) Glucose-induced increases in renal hemodynamic function. Possible modulation by renal prostaglandins. Diabetes 34: 360-364

67. Estmatjes E, Fernandez MR, Halperin I et al. (1985) Renal hemodynamic abnormalities in patients with short term insulindependent diabetes mellitus: role of renal prostaglandins. J Clin Endocrinol Metab 60: 1231-1236

68. Jensen PK, Steven K, Blaehr H, Christiansen JS, Parving H-H (1986) Effects of indomethacin on glomerular hemodynamics in experimental diabetes. Kidney Int 29:490-495

69. Craven PA, Caines MA, De Rubertis FR (1987) Sequential alterations in glomerular prostaglandin and thromboxane synthesis in diabetic rats: relationship to the hyperfiltration on early diabetes. Metabolism 36: 95-103

70. Barnett R, Scharschmidt L, Ko Y-H, Schlondorff D (1987) Comparison of glomerular and mesangial prostaglandin synthesis and glomerular contraction in two rat models of diabetes mellitus. Diabetes 36: 1468-1475

71. Ledbetter S, Copeland EJ, Noonan D, Vogeli G, Hassell JR (1990) Altered steady-state mRNA levels of basement membrane proteins in diabetic mouse kidneys and thromboxane synthase inhibition. Diabetes 39: 196-203

Prof. R.G.Larkins

University of Melbourne

Department of Medicine

Royal Melbourne Hospital

Victoria 3050

Australia 